\title{
COMPARATIVE STUDY OF BATCHWISE SOLVENT EXTRACTION AND THE MICROWAVE ASSISTED EXTRACTION METHOD FOR THE PURIFICATION OF TRIGLYCERIDE FOR BIODIESEL FEEDSTOCK FROM CRUDE CALOPHYLLUM INOPHYLLUM OIL (CCIO)
}

\author{
Hakun Wirawasista Aparamarta ${ }^{1 *}$, Setiyo Gunawan ${ }^{1}$, Badril Azhar $^{1}$, Hanggoro T. Aditya $^{1}$, \\ Arief Widjaja ${ }^{1}$, Yi Hsu $\mathrm{Ju}^{2}$ \\ ${ }^{1}$ Department of Chemical Engineering, Institut Teknologi Sepuluh Nopember, Surabaya 60111, \\ Indonesia \\ ${ }^{2}$ Department of Chemical Engineering, National Taiwan University of Science and Technology, Taipei \\ 106-07, Taiwan
}

(Received: July 2018 / Revised: October 2018 / Accepted: April 2019)

\begin{abstract}
Recently, edible oil has been employed for biodiesel feedstocks. However, the use of such oil to fulfil energy demand raises certain problems, such as the sustainability of the practice due to its competition with food. Therefore, it is necessary to obtain alternative resources from non-edible oil. One promising biodiesel feedstock from a non-edible oil source is crude Calophyllum inophyllum oil (CCIO) because of its high oil content. The highest oil content in CCIO is triglyceride (TG), which influences biodiesel production. The higher content of TG results in a higher yield of biodiesel. Previous research on the conversion of CCIO into biodiesel with an environmentally friendly purification method and fast separation of compounds is limited. In this work, batchwise solvent extraction (BSE) and microwave-assisted extraction (MAE) were compared to achieve an effective and efficient method for TG purification. By using the microwave method with 450 watts of power for 30 minutes, a high content of TG was obtained. It was found that TG content increased significantly, from $75.99 \%$ to $83.46 \%$. Using the BSE method with a mixture of petroleum ether-methanol (methanol 25\%), a solvent-to-oil mass ratio of 5:1, time for the first 2 stages (48 hours), the TG content obtained was $82.02 \%$. The data obtained for the microwave method are almost equivalent to the first 2 stages of BSE with regard to TG content ( $83.46 \%$ compared to $82.02 \%$ ) and almost 0.01 times shorter than BSE (30 minutes compared to 48 hours).
\end{abstract}

Keywords: Batchwise solvent extraction; Biodiesel; Free fatty acid; Microwave-assisted extraction; Triglycerides

\section{INTRODUCTION}

Along with annual economic growth, population and regional development, the need for energy is also increasing. Fuel consumption increased rapidly from 2009 to 2015, from around 1,297,000 barrels/day (bpd) to $1,628,000 \mathrm{bpd}$, or an increase of $20.3 \%$. In six years, there was an increase in fuel consumption of $331,000 \mathrm{bpd}$. Indonesia's oil consumption is showing an increasing trend due to its growing population and economy. As domestic production cannot meet domestic demand, Indonesia imports 350,000 to 500,000 barrels of fuel per day from several countries.

\footnotetext{
${ }^{*}$ Corresponding author's email: hakun2397@gmail.com, Tel. +62-31-5946240
}

Permalink/DOI: https://dx.doi.org/10.14716/ijtech.v10i3.2920 
The country needs more fuel oil to meet domestic demand, so an alternative source of renewable energy is needed.

Biodiesel is one of the solutions to fulfil domestic demand in Indonesia. Recently, biodiesel feedstock has used used edible oil, such as palm, soy bean, sunflower and rapeseed. The use of edible oil to meet energy demand poses many problems, such as the sustainability of the practice due to its competition with food, land and water (Kansedo et al., 2009). This competition will increase the price of raw materials, and almost $80 \%$ of the cost of biodiesel production is that of the raw materials (Saraf \& Thomas 2007). The selection of the underlying raw material is based on the oil content and yield of the plant used as biodiesel feedstock, so that production costs can be lower (Gui et al., 2008). This oil content is usually determined by establishing the triglyceride (TG) levels which are mostly found in oil; on this basis, C. Inophyllum is one of the best feedstocks for biodiesel production. Aparamarta et al. (2018) report that the oil content of $C$. inophyllum is $70.38 \%$.

The biggest challenge in using crude C. inophyllum oil as biodiesel feedstock is the large amount of free fatty acids (FFA) it contains. The level of these in oil should be below $3 \%$ for alkalinecatalyzed transesterification (Ribeiro et al., 2011) and lower than $0.3 \%$ for edible oil (SNI, 2002). A high level of FFA will cause a saponification reaction, which can decrease biodiesel yields, hinder the separation of ester from glycerin, and reduce the formation rate of biodiesel (Thiruvengadaravi et al., 2012). Therefore, methods for TG purification are applied to achieve an optimal yield of biodiesel. Existing methods are chemical purification, which involves chemicals that can be hazardous in handling and which can damage the environment. Therefore, it is necessary to find a solution comprising an easy method to provide better separation of FFA and TG and which does not damage the environment. One approach is the batchwise solvent extraction (BSE) method, as used by Aparamarta et al. (2016), who succeeded in separating TG and FFA with purity and recovery of TG as the indicator for the effective separation of nonpolar lipid fraction from crude $C$. inophyllum seed oil. The resulting product had a TG content of $98.53 \%$ and FFA of $0.35 \%$. However, this method requires a long separation time process.

Therefore, this study involved the addition of the microwave-assisted extraction (MAE) method to the TG purification process. MAE is an extraction process that utilizes the energy generated by microwaves with a frequency of $0.30-300 \mathrm{GHz}$ in the form of electromagnetic non-ionization radiation. The advantages of the MAE method are that it has a lower solvent consumption, and a significantly reduced extraction time compared to conventional methods (Cercado et al., 2018). In addition, it has a better heating process, less energy consumption and increased yields (Liu et al., 2013). The heating process acts as the driving force to extract the triglyceride compound from the biological matrix in a shorter period of time (Patil et al., 2011). The method was used by Leong et al. (2016), who used microwave heating to obtain pyrolyzed oil from crude glycerol.

The purpose of this research is to study an effective method for TG purification as a biodiesel feedstock. The alternative raw material selected was Calophyllum inophyllum, on the basis of oil content and yield. The technology selected was batchwise solvent extraction (BSE) and microwave-assisted extraction (MAE).

\section{METHODS}

\subsection{Materials}

The crude Calophyllum inophyllum oil (CCIO) was obtained from Koperasi Jarak Tani Lestari (Central Java, Indonesia), while thin layer cromatography (TLC) aluminum plates $(20 \mathrm{~cm} \times 20$ $\mathrm{cm} \times 250 \mu \mathrm{m}$ ) were purchased from Merck (Darmstadt, Germany). Silica gel was purchased from Merck (New York, USA), and standard fatty acids, triolein and tripalmitin were obtained from Sigma Chemical Company (St. Louis, MO). All the solvents and reagents were either high- 
performance liquid chromatograpy (HPLC) grade or analytical-grade, and were obtained from commercial sources.

\subsection{Separation of TG from Crude $C$. inophyllum Oil by Batchwise Solvent Extraction (BSE)}

The separation of TG from crude $C$. inophyllum oil was described by Aparamarta et al. (2016). The method uses the concept of nonpolar and polar lipids; in this study, polar solvent (methanol) and nonpolar solvent (petroleum ether) were used. The ratio of crude oil to solvent was 1:5. The solvent was a mixture of petroleum ether (PE) and methanol (ME), at a ratio of PE:ME of 3:1. The crude oil and solvent were put into a beaker and the mixture was stirred at $400 \mathrm{rpm}$ at room temperature for $25 \mathrm{~min}$. It was then separated by a separatory funnel, resulting in two layers (polar and nonpolar lipids). The nonpolar lipid was taken and washed by methanol until 10 stages. The results were analyzed by GC (gas chromatography) and TLC.

\subsection{Separation of TG from Crude $C$. inophyllum Oil by Microwave Assisted Extraction (MAE)}

For the MAE method, the solvent and crude variables used were the same as in the BSE method. After they had been stirred, the mixture was put into a single neck flask, at 150, 300, 450 and 600 watts, for periods of 30, 60 and 90 minutes. The results were analyzed by GC and TLC.

\subsection{Thin Layer Chromatography (TLC) Analysis}

TLC was applied to qualitatively analyse the sample using authentic standards, as described by Gunawan et al. (2008a). TLC paper stained by the sample was immersed in a mobile phase of hexane:ethyl acetate:acetic acid at a ratio of 90:10:1 (v/v/v).

\subsection{Gas Chromatography Mass Spectrometry (GC) Analysis}

GC was used to ascertain the level of TG (triglycerides), FFA (free fatty acid), DG (diacylglycerols) and MG (monoacylglycerols), as described by Aparamarta et al. (2016). It was performed on a Shimadzu GC-2010 gas chromatograph (made in Japan), equipped with a flame ionization detector. Separations were carried out on a ZB-5HT.

\section{RESULTS AND DISCUSSION}

Feedstocks are a key aspect of implementing biodiesel in Indonesia. Generally, their cost comprises around 70-80\% of the total biodiesel production cost (Du et al., 2004). For this reason, yield and oil content are important factors in deciding the suitability of a crop as a biodiesel feedstock, as they can lower biodiesel production costs (Gui et al., 2008). The largest component in oil content is TG (Aparamarta et al., 2016), which is a key component in producing higher yields in biodiesel production. The other key component is FFA. The level of this compound in the oil should be below $3 \%$ for alkaline-catalyzed transesterification (Ribeiro et al., 2011) Sources of non-edible oil can be seen in Table 1. From the table, C. Inophyllum shows potential for biodiesel feedstock.

Calophyllum inophyllum is a mangrove crop that fruits twice a year, in May and November. The fruit is a spherical to ovoid drupe, $25-50 \mathrm{~mm}$ in diameter, with a thin, compact and smooth outer layer, and is greyish-green in color (Aparamarta et al., 2016). CCIO was used in this study as the raw material. It is dark green and liquid at room temperature. Using GC analysis, the content of the CCIO was determined; the TG and FFA content was $75.99 \%$ and $12.21 \%$, respectively. A previous study found that the TG content of CCIO was in the range of 40-73\% (Atabani \& César, 2014), while another found that CCIO comprised 70.38\% TG and 8.51\% FFA (Aparamarta et al., 2016). This difference of oil content was attributed to the Calophyllum inophyllum cultivar, time since harvest, and diverse agronomic factors (Aparamarta et al., 2017). 
In this study, TLC analysis was used to ascertain the relative polarity of each compound in the crude $C$. inophyllum seed oil. It was found that the most nonpolar one was TG, followed by DG, FFA, MG and gum. The observed TLC spots were similar to previous work on soybean oil deodorized distillate (SODD). Typical results from the TLC analysis of SODD show the presence of squalene, fatty acid steryl esters, TG, tocopherols, DG, FFA and free phytosterols (Gunawan et al., 2008b).

Table 1 Non-edible sources of biodiesel feedstock

\begin{tabular}{lccccl}
\hline $\begin{array}{c}\text { Feedstock } \\
\text { Non-Edible Oil }\end{array}$ & Source & $\begin{array}{c}\text { Oil Content } \\
(\mathrm{wt} \%)\end{array}$ & $\begin{array}{c}\text { Yield } \\
(\text { Kg oil/ ha) }\end{array}$ & $\begin{array}{c}\text { Cetane } \\
\text { Number }\end{array}$ & Reference \\
\hline C. inophyllum & Seed & $40-73$ & 4680 & 57 & Singh \& Singh (2010) \\
Croton tiglium & Seed & $30-45$ & - & - & Azam et al. (2005) \\
Jatropha curcas L. & Seed & $20-60$ & 1590 & $33.7-51$ & Sahoo et al. (2007) \\
Madhuca indica & Seed & $35-50$ & - & - & Azam et al (2005) \\
\hline
\end{tabular}

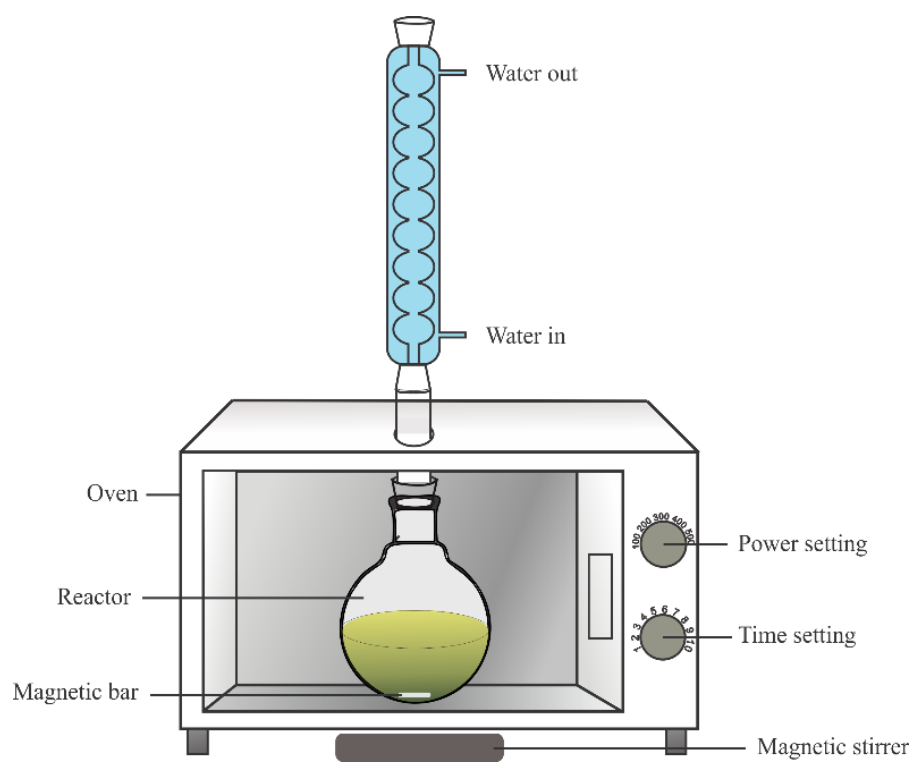

Figure 1 MAE method

In this study, MAE and BSE were applied in the TG purification. The BSE method increases the purity of TG by washing the CCIO with methanol, so at each stage methanol was added. On the other hand, the MAE method achieves increased TG purity. The MAE scheme can be seen in Figure 1. The BSE and MAE method steps were used to replace the chemical process of refined vegetable oil production, such as degumming, neutralization and bleaching. From the BSE and MAE results, it was separated became two layer, namely the Non-Polar Lipid Fraction (NPLF) and Polar Lipid Fraction (PLF) (Aparamarta, 2018). Furthermore, the content of TG and FFA was chosen as the indicator for the effective separation of NPLF from crude $C$. inophyllum seed oil. 


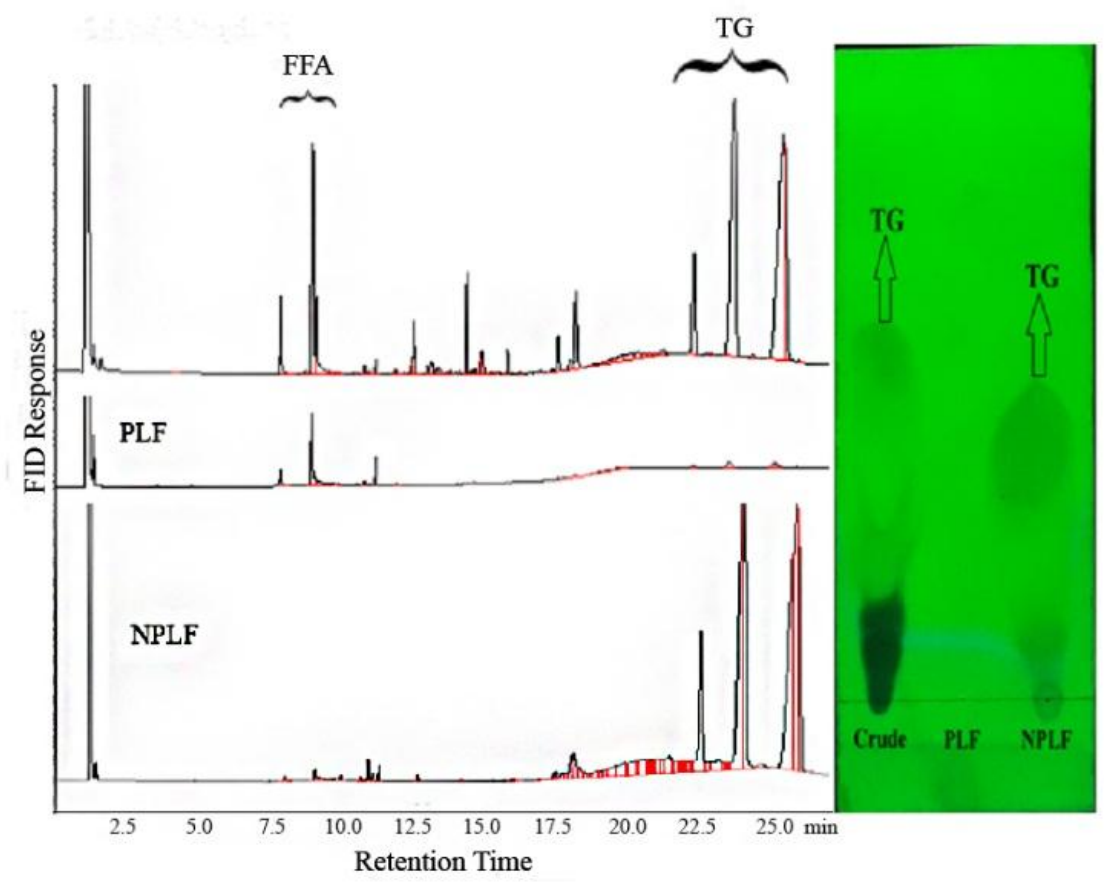

(a)

(b)

Figure 2 Results of the: (a) HTGC; and (b) TLC developed in the mobile phase (90:10:1) in the CCIO with batchwise solvent extraction

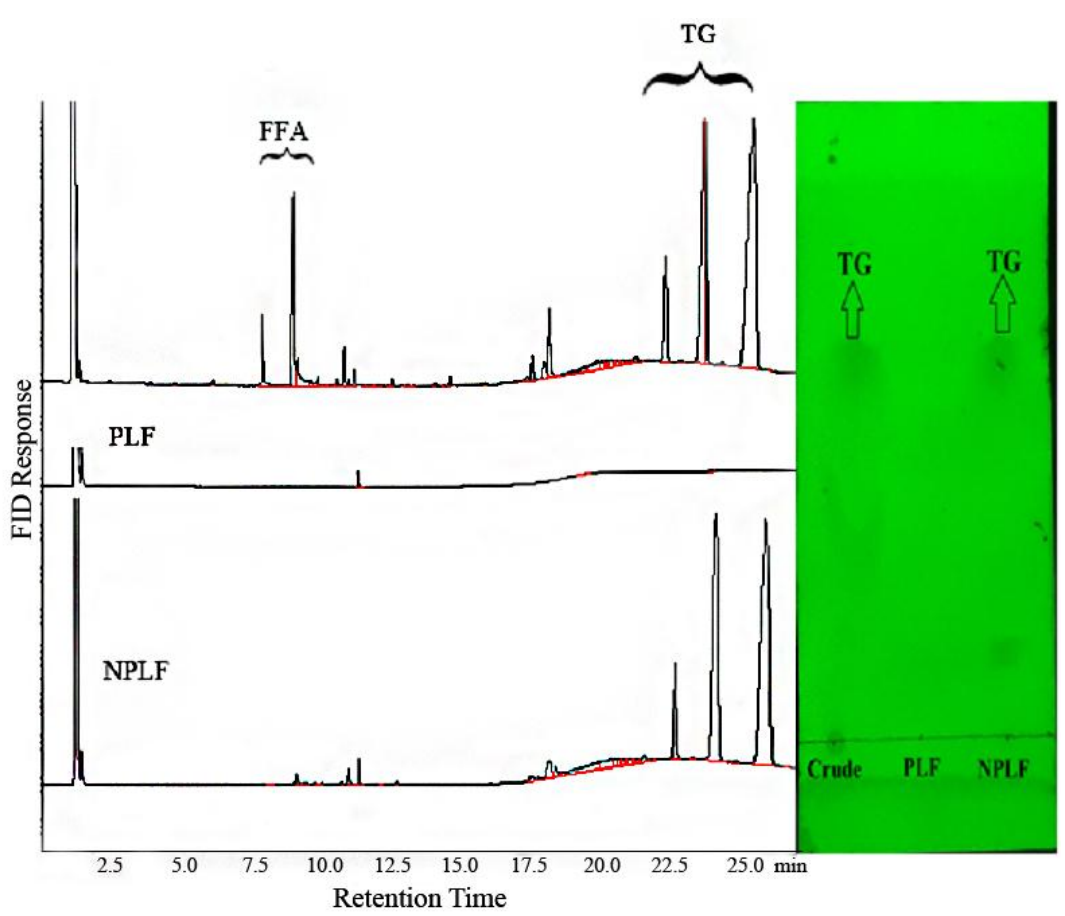

(a)

(b)

Figure 3 Results of the: (a) HTGC; and (b) TLC developed in the mobile phase (90:10:1) in the CCIO with microwave assisted extraction analysis

The CCIO before and after purification was tested by HT-GC and TLC to ascertain the separation and content of the TG and FFA in the CCIO. The TLC and HT-GC analyses of the crude oil, NPLF and PLF are shown in Figures 2a, 2b, 3a and 3b. From these figures, it is clear that TG was successfully separated in the NPLF, as confirmed by the TLC and HT-GC analyses. 
From Table 2, it can be seen that the content of TG increased from $75.99 \%$ to $83.46 \%$ and that of FFA decreased from $12.21 \%$ to $7.50 \%$ at 450 watts and for 30 minutes. To achieve this result, MAE only needed 30 minutes. The optimum condition was at a power of 450 watts and with a time of 30 minutes for the MAE method.

The BSE method, on the other hand, needed 145 hours (around 6 days) for completion and involved ten stages, as can be seen in Table 3. The TG content increased from $75.99 \%$ to $94.24 \%$ and that of FFA decreased from $12.21 \%$ to $0.62 \%$. According to the results, the optimum stage was stage 9. Comparing the results from stages 8 and 9, the TG level in stage 9 increased and the FFA content decreased. From stages 9 to 10, the FFA level decreased, but the TG level also decreased. It was probably after stage 9 that the TG content convert became FFA.

Table 2 Composition of NPLF according to power and time in the MAE method

\begin{tabular}{cccc}
\hline \multirow{2}{*}{ Power (watts) } & \multirow{2}{*}{ Time (minutes) } & \multicolumn{2}{c}{ Compounds } \\
\cline { 2 - 4 } & & TG $(\%)$ & FFA $(\%)$ \\
\hline \multirow{2}{*}{150} & 30 & 79.36 & 11.95 \\
& 60 & 79.67 & 9.92 \\
& 90 & 80.94 & 8.89 \\
\hline \multirow{3}{*}{300} & 30 & 76.47 & 9.31 \\
& 60 & 79.54 & 9.30 \\
450 & 90 & 81.21 & 9.14 \\
& 30 & 83.46 & 7.50 \\
& 60 & 81.66 & 8.45 \\
& 90 & 79.86 & 8.52 \\
\hline \multirow{2}{*}{600} & 30 & 81.67 & 8.11 \\
& 60 & 80.24 & 9.39 \\
& 90 & 77.68 & 10.07 \\
\hline
\end{tabular}

Table 3 Composition of NPLF at each stage in the BSE method

\begin{tabular}{cccc}
\hline \multirow{2}{*}{ Stage } & \multirow{2}{*}{ Time (hours) } & \multicolumn{2}{c}{ Compounds } \\
\cline { 3 - 4 } & & TG $(\%)$ & FFA (\%) \\
\hline 1 & 24 & 80.46 & 10.59 \\
2 & 24 & 82.02 & 6.14 \\
3 & 22 & 86.35 & 4.77 \\
4 & 20 & 89.77 & 2.59 \\
5 & 18 & 91.98 & 1.36 \\
6 & 12 & 91.84 & 1.61 \\
7 & 9 & 93.77 & 0.88 \\
8 & 7 & 94.19 & 0.81 \\
9 & 6 & 94.67 & 0.63 \\
10 & 3 & 94.24 & 0.62 \\
\hline
\end{tabular}

\subsection{Effect of Time in the BSE Method}

Separation of the polar and non-polar compounds in C. inophyllum oil using the batchwise solvent extraction method takes up to 142 hours (5.92 days), as can be seen in Figure 4 and Table 3. The separation time decreases at the higher stages. The starting stage has a longer separation time compared to the next because at the first stage the polar compound content in the $C$. inophyllum oil is higher than at the other stages (Aparamarta et al., 2016). At the early stages, the PLF fraction is dark green. However, as the stages increase, this becomes bright green, which shows the polar and non-polar separation process has been successful. 
Stage Time in Hour with Percentage Error

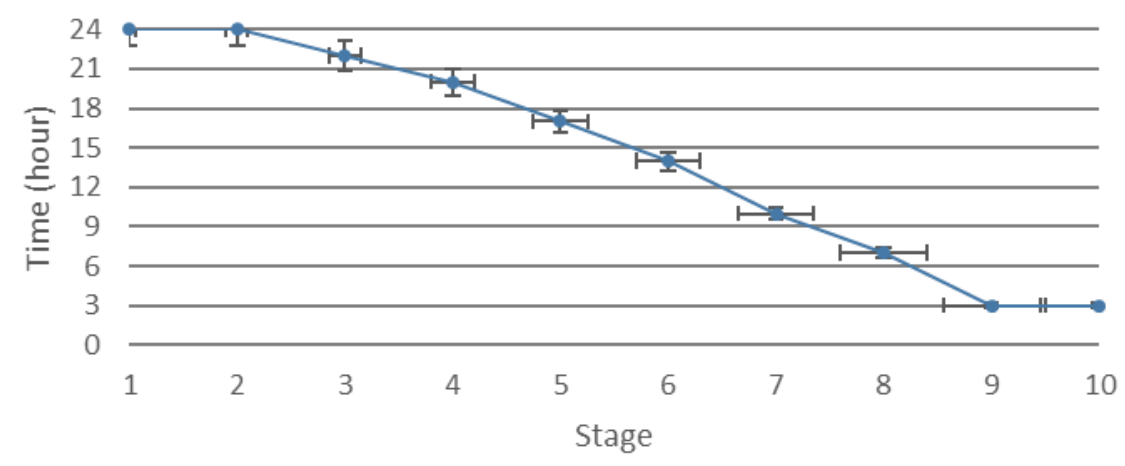

Figure 4 Time for each stage in BSE

\subsection{Effect of Time in the MAE Method}

The process efficiency of MAE depends on the operating conditions selected, such as power and time of microwave operation, ratio of solid to solvent, and temperature (Zhang et al., 2011). In this study, the extraction times used were 30, 60 and 90 minutes.

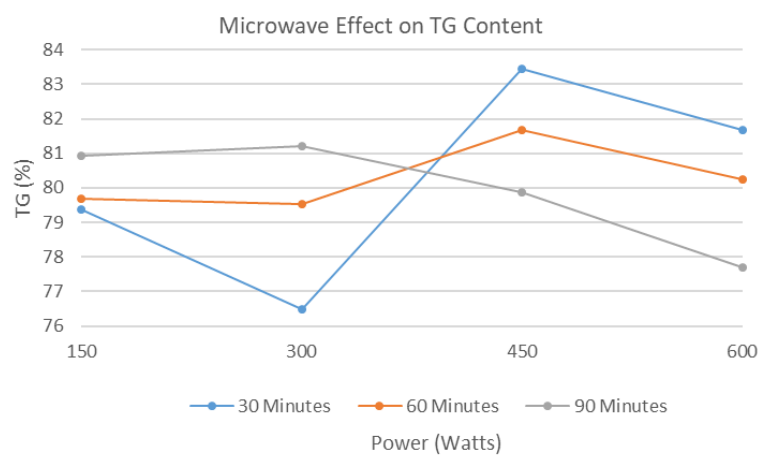

(a)

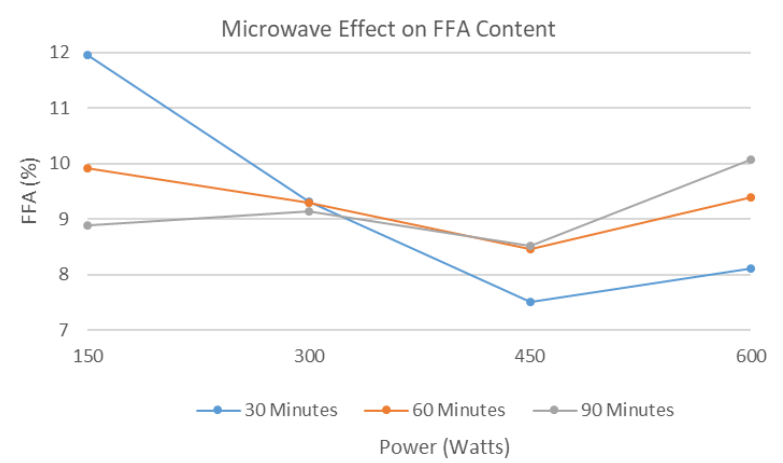

(b)

Figure 5 Effect of time for the: (a) TG; and (b) FFA parameters in the MAE method

From Figure 5 and Table 2, it can be seen that the highest percentage of TG compound, 83.46\%, was obtained at 30 minutes, with that of free fatty acid (FFA) at 7.5\%. The lowest percentage of TG, $79.86 \%$, was obtained at 90 minutes, with that of FFA at $8.52 \%$, at 450 and 600 watts. An increase in extraction time results in a decrease in TG content. A longer time extraction changes the concentration of the solution and reduces the extraction power (Liu et al., 2013). Extra time may result in errors in obtaining the concentration, as a longer extraction time means the volatile component in the TG compound may evaporate, leading to a decrease in the extraction yield (Karakaya et al., 2014).

\subsection{Effect of Power in the MAE Method}

Power is the amount of energy sent per unit of time (joules/sec). Power and temperature are related; higher power can increase the operating temperature above the boiling point of the solvent and produce an increase in TG in C. inophyllum oil (Erliyanti \& Rosyidah, 2017). Power acts as a driving force to break down the cell structure of the membrane, so the amount of TG compound increases. In general, the addition of power will increase this amount and speed up the extraction time. Power will control the amount of energy received by the material and be converted into heat energy. This energy will affect the purification process of the triglyceride 
compounds. The power used in this research was 150, 300, 450 and 600 watts; its effects are shown in Figure 6.

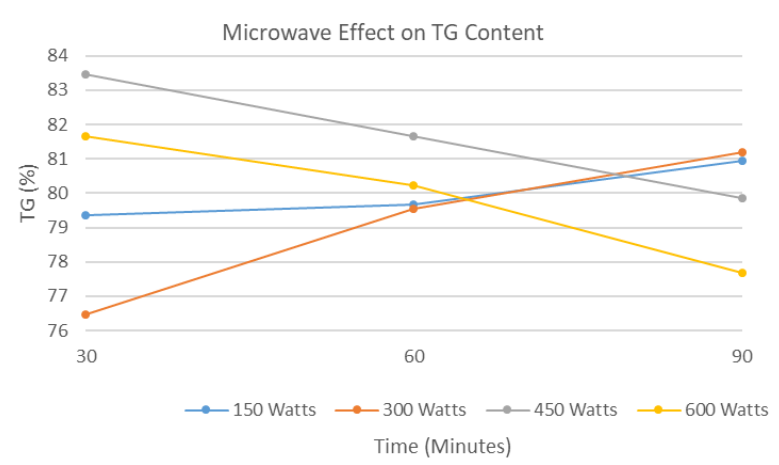

(a)

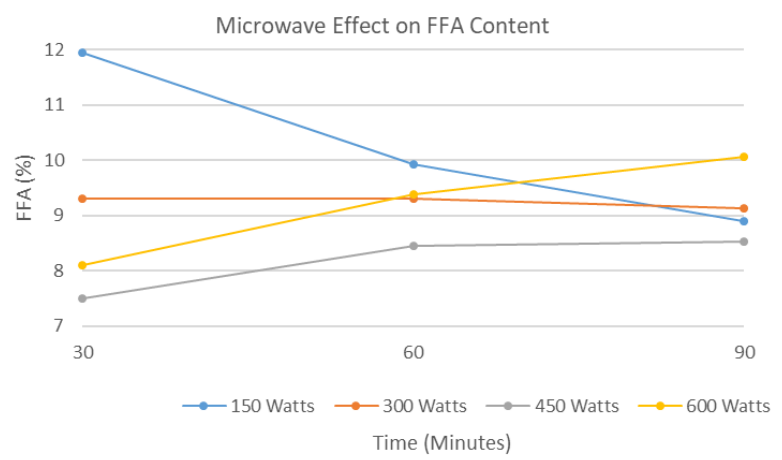

(b)

Figure 6 Effect of power on the (a) TG and (b) FFA parameters in the MAE method

From Figure 6, it can be seen that the optimum variables are 450 watts and 30 minutes. With these, the highest percentage of TG, $83.46 \%$, was obtained, and the lowest percentage of FFA, $7.5 \%$. An increase in power results in an increasing percentage of TG, as such an increase makes the operating temperature rise and the extraction process becomes more effective. Increasing temperature is the effect of the breakdown of membrane cell structures by microwave irradiation (Ferhat et al., 2006). Greater energy is received by the material to be converted into heat, so the level of triglyceride compounds from $C$. inophyllum oil will be greater. However, the TG in $C$. inophyllum oil decreases at 600 watts of power, while the FFA increases with increases in the microwave power setting and time (Sengar et al., 2015). This is due to TG reverting to FFA, so the FFA increases. TG content was found to decrease as power was increased from 450 to 600 watts, as shown in Figure 6a; on the other hand, the FFA content increased as power increased from 450 to 600 watts, as shown in Figure $6 \mathrm{~b}$.

The percentage of TG and FFA in the MAE method with 450 watts of power and at 30 minutes, and the second stage of BSE method is almost the same. The percentages of TG were $83.46 \%$ and 82.02 , whereas those of FFA were $7.50 \%$ and $6.14 \%$, respectively. In the BSE method, to achieve this result two stages and 48 hours are needed, whereas in the MAE method only 30 minutes are necessary. Therefore, it can be said that the MAE method can replace the first two stages of BSE method. In line with the results, MAE is a promising method for TG purification as it is more efficient than the first two stage of BSE method.

\section{CONCLUSION}

High purification of triglyceride (TG) was successfully obtained from crude Calophyllum inophyllum via batchwise solvent extraction (BSE) and microwave assisted extraction (MAE). The data obtained for the MAE method are almost equivalent to the first two stages BSE for TG content (83.46\% compared to $82.02 \%$ ) and almost 0.01 times shorter than BSE (30 minutes compared to 48 hours). The optimum conditions using the BSE method were achieved at stage 9, with percentages of TG of $94.67 \%$ and of FFA of $0.63 \%$. For MAE, the optimum conditions were obtained at 450 watts and 30 minutes, resulting in corresponding figures of $83.46 \%$ and $7.5 \%$. The power and extraction time variables had a significant influence on the percentages of TG compound in the $C$. inophyllum oil.

\section{ACKNOWLEDGEMENT}

This work was supported by a grant (138/Addendum/ITS/2019) provided by the Institute of 
Research and Public Services (LPPM), Institut Teknologi Sepuluh Nopember (ITS), Surabaya, Indonesia.The author would like to thank Mr. Gunawan, Mr. Rayhan, and Mr. Adya for their excellent technical support.

\section{REFERENCES}

Aparamarta, H.W., Saputra, T., Claratika, A., Ju, Y.H., Gunawan, S., 2016. Separation and Purification of Triacylglycerols from Nyamplung (Calophyllum inophyllum) Oil by Batchwise Solvent Extraction. Industrial Engineering Chemistry Research, Volume 55(11), pp. 3113-3119

Aparamarta, H.W., Anggraini, D., Istianingsih, D., Susanto, D.F., Widjaja, A., Ju, Y.H., Gunawan, S., 2017. Fatty Acid Fragmentation of Triacyglycerol Isolated from Crude Nyamplung Oil. In: AIP Conference Proceedings, Volume 1840(1), pp. 060004

Aparamarta, H.W., Qadariyah, L., Gunawan S., Ju Y.H., 2018. Separation and Identification of Fatty Acid in Triacyglycerol Isolated from Calophyllum inophyllum Oil. Asia Research Publishing Network, Volume 13(2), pp. 442-451

Atabani, A.E., César, A.D. 2014. Calophyllum Inophyllum L. -A Prospective Non Edible Biodiesel Feedstock. Study of Biodiesel Production, Properties, Fatty Acid Composition, Blending and Engine Performance. Renewable and Sustainable Energy Reviews, Volume 37, pp. 644-655

Azam, M.M., Waris, A., Nahar, N.M., 2005. Prospects and Potential of Fatty Acid Methyl Esters of Some Non-traditional Seed Oils for Use as Biodiesel in India. Biomass and Bioenergy, Volume 29(4), pp. 293-302

Cercado, A.P.I., Ballesteros, F.C., Capareda, S.C., 2018. Biodiesel from Three Microalgae Transesterification Processes using Different Homogenous Catalysts. International Journal of Technology, Volume 9(4), pp. 645-651

Du, W., Xu, Y.Y., Liu, D., Zeng, H., 2004. Comparative Study on Lipase-catalyzed Transformation of Soybean Oil for Biodiesel Production with Different Acyl Acceptors. Journal of Molecular Catalysis B: Enzymatic, Volume 30(3-4), pp. 125-129

Erliyanti, N.K., Rosyidah, E., 2017. Pengaruh Daya Microwave terhadap Yield pada Ekstraksi Minyak Atsiri dari Bunga Kamboja (Plumeria alba) Menggunakan Metode Microwave Hydrodistillation (The Effect of Microwave Power on Extraction Yield of Essential Oil from Cambodian Flowers (Plumeria alba) using Microwave Hydrodistillation Method). Jurnal Rekayasa Mesin (Journal of Machine Engineering), Volume 8(3), pp. 175-178

Ferhat, M.A., Meklati, B.Y., Smadja, J., Chemat, F., 2006. An Improved Microwave Clevenger Apparatus for Distillation of Essential Oils from Orange Peel. Journal of Chromatography A, Volume 1112(1-2), pp. 121-126

Gui, M.M., Lee, K.T., Bhatia S., 2008. Feasibility of Edible Oil vs Non Edible Oil vs Waste Edible Oil as Biodiesel Feedstock. Energy, Volume 33(11), pp. 1646-1653

Gunawan, S., Fabian, C. Ju, Y. H., 2008a. Isolation and Purification of Fatty Acid Steryl Esters from Soybean Oil Deodorizer Distillate. Industrial Engineering Chemistry Research, Volume 47(18), pp. 7013-7018

Gunawan, S., Kasim, N.S., Ju, Y.H., 2008b. Separation and Purification of Squalene from Soybean Oil Deodorizer Distillate. Separation and Purification Technology, Volume 60(2), pp. $128-135$

Kansedo, J., Lee K.T., Bhatia S., 2009. Cerbera Odollam (Sea Mango) Oil as A Promising Nonedible Feedstock for Biodiesel Production. Fuel, Volume 88(6), pp. 1148-1150

Karakaya, S., El S.N., Karagozlu, N., Sahin, S., Sumnu, G., Bayramoglu, B., 2014. MicrowaveAssisted Hydrodistillation of Essential Oil from Rosemary. Journal of Food Science and Technology, Volume 51(6), pp. 1056-1065 
Leong, S.K., Lam, S.S., Ani, F.N., Ng, J-H., Chong, C.T., 2016. Production of Pyrolyzed Oil from Crude Glycerol using a Microwave Heating Technique. International Journal of Technology, Volume 7(2), pp. 323-331

Liu, W., Yin, P., Liu, X., Chen, W., Chen, H., Liu, C., Qu, R., Xu, Q., 2013. Microwave Assisted Esterification of Free Fatty Acid Over a Heterogeneous Catalyst for Biodiesel Production. Energy Conversion and Management, Volume 76, pp. 1009-1014

Patil, P.D., Gude, V.G., Mannarswamy, A., Cooke, P., Munson-McGee, S., Nirmalakhandan, N., Lammers, P., Deng, S., 2011. Optimization of Microwave Assisted Transesterification of Dry Algal Biomass using Response Surface Methodology. Bioresource Technology, Volume 102(2), pp. 1399-1405

Ribeiro, A., Castro, F., Carvalho, J., 2011. Influence of Free Fatty Acid Content in Biodisel Production on Non-edible Oils. In: Wastes: Solutions, Treatments and Opportunities $1^{\text {st }}$ International Conference, Guimarães Portugal, pp. 12-14

Saraf, S., Thomas, B., 2007. Influence of Feedstock and Process Chemistry on Biodiesel Quality. Process Safety and Environmental Protection, Volume 85(5), pp. 360-367

Sahoo, P.K., Das, L.M., Babu, M.K.G., Naik, S.N., 2007. Biodiesel Development from High Acid Value Polanga Seed Oil and Performance Evaluation in a CI Engine. Fuel, Volume 86(3), pp. 448-454

Sengar, G., Sharma, H.K., Kumar, N., 2015. Effect of Microwave Heating on Physico-chemical and Thermal Behavior of Blended Fat. International Food Research Journal, Volume 22(1), pp. 295-303

Singh, S.P., Singh, D., 2010. Biodiesel Production through the Use of Different Sources and Characterization of Oils and Their Esters as the Substitute of Diesel: A Review. Renewable and Sustainable Energy Reviews, Volume 14(1), pp. 200-216

SNI 01-3741, 2002. Indonesian Standart of Cooking Oil

Thiruvengadaravi, K.V., Nandagopal, J., Baskaralingam, P., Sathya Selva Bala, V., Sivanesan, S., 2012. Acid-catalyzed Esterification of Karanja (Pongamia pinnata) Oil with High Free Fatty Acids for Biodiesel Production. Fuel, Volume 98, pp. 1-4

Zhang, H., Yang, X., Wang, Y., 2011. Microwave Assisted Extraction of Secondary Metabolites from Plants: Current Status and Future Directions. Trends in Food Science \& Technology, Volume 22(12), pp. 672-688 